Journal of CONTACT LENS RESEARCH \& SCIENCE

Review Article

\author{
COMPLIANCE USING SCLERAL LENSES \\ Daddi Fadel, Dip Optom (IT), FSLS ${ }^{1}$ and Mindy Toabe, OD FAAO FSLS ${ }^{2}$ \\ ${ }^{1}$ Private Practice, Rieti, Italy \\ ${ }^{2}$ MetroHealth Medical Center Senior Clinical Instructor, Case Western Reserve University, School of \\ Medicine, Cleveland Ohio
}

Submitted: November 27, 2017. Accepted: March 3, 2018. Published: April 19, 2018.

\begin{abstract}
The rise in scleral contact lens ( $\mathrm{ScCL}$ ) use may increase the risk of complications including microbial keratitis. Patient understanding of hygiene as well as care and handling of ScCLs is crucial to prevent the increase of complications.

This manuscript presents a review of the modalities and implications of the hygiene and care of scleral lenses, storage case, and devices. Also, correct application and removal techniques are explained in detail with recommendations on instructions for ScCLwearers and verification of patient compliance are provided. Adverse events are rarely reported in literature but clinicians need to understand how to deliver appropri-ate information and instruction regarding basic rules of hygiene, contact lens care and handling to patients to prevent and minimize associated infections. It is fundamental that practitioners learn how to impart knowledge to their patients during every encounter including follow-up visits regarding proper management and compliance with ScCLs. Also, a dialogue with the patient is essential to develop empathy allowing for greater collaboration and compliance raising the fitting rate, success and patient's overall satisfaction.
\end{abstract}

Modern scleral lenses (ScCLs) made with high Dk materials are gaining popularity amongst practitioners. ScCLs have decreased complications related to hypoxia compared to earlier ScCLs made in PMMA materials. ${ }^{1-5}$ However, new complications have emerged with increased ScCL use due to lens handling. Additionally, ScCLs are indicated for a wide range of ocular conditions including ocular surface disease which may be a further risk factor for developing infections as well as patients who may be taking oral and/or topical corticosteroids which may decrease the immune defense system. ${ }^{6-12}$

The SCOPE (Scleral Lenses in Current Ophthalmic Practice: an Evaluation) study surveyed 989 practitioners treating 85,000 patients with ScCLs and reported that the most common complication (462 patients) was caused by lens handling (application and removal). An additional 148 patients had issues due to poor patient compliance using different solutions other than those recommended by the practitioner such as contact lens cleaner instead of a conditioning/ disinfecting solution to store lenses or saliva to clean lenses. Seventy patients were affected by microbial keratitis (MK). ${ }^{13}$ The most important factors related to MK using RGP lenses are: rinsing and storing lenses with tap water, ${ }^{14}$ topping off contact lens solution, using disinfecting solution longer than 3 months ${ }^{15,16}$ and wearing lenses while sleeping as with orthokeratology. ${ }^{17}$ 
Other recent studies have confirmed that MK is indeed a complication with ScCL wear due to poor compliance with ScCL care. ${ }^{6,10,18,19}$

Hygiene and compliance are crucial for preventing the incidence of complications related to ScCL use. This paper will discuss the current recommendations and the importance of compliance with ScCLs.

\section{COMPLIANCE USING SCLERAL LENSES}

Compliance is typically defined as the process of fulfilling instructions within a regimen of treatment. ${ }^{20}$ Poor compliance may cause discomfort, eye surface alterations, and even reduction of visual performance. The failure to comply may be due to the lack of information and instructions given by clinicians regarding basic rules of hygiene and contact lens care and handling. ${ }^{15}$ Another factor may be time requirements and effort needed to maintain proper contact lens aftercare. Patients may also misperceive the importance of aftercare. Lens wear recommendations tend to be primarily preventive in nature, whereby patients do not benefit instantly from proper aftercare leading to future complications from failure with suggested instructions. ${ }^{21,22}$

Patients who are aware about safe ScCL wear are more likely to be compliant. ${ }^{23}$ Further, clinicians need to be assured that guidelines are followed properly. Unfortunately, clinicians may not dedicate the necessary time to achieve this task by having a dialogue with patients. It has been reported that practitioners are not able to predict if a patient will be compliant. Doctor-patient communication has been reported to be commonly clinician-centred rather than patientcentered, speaking $70 \%$ of the words and asking closed-ended questions that limited patients to answer with only "yes/no" or briefly. Patients should take a more active role in the exam and with open dialogue with encouragement to ask their own questions. Filling a questionnaire or compliance survey may be less imposing, permitting them to feel free in answering thereby preventing false answers. ${ }^{24}$

A dialogue with patients may increase empathy, level of collaboration and compliance. This discussion is important with ScCL wearers because of their ocular conditions which may affect their psychology.
It should be acknowledged that these patients may be more diligent with instructions because ScCLs may change their quality of life.

It is equally important that practitioners educate patients to remove ScCLs daily and to contact their eye-care professional if the patient experiences irritation, worsening eye pain, light sensitivity, sudden blurry vision, or unusually watery eyes or discharge.

\section{HAND WASHING}

While the significance of washing hands prior to handling contact lenses is well known and largely suggested there are very few practitioners who advise patients on how to wash their hands. The Royal College of Nursing (RCN) hand washing technique used in medical fields provides efficient protection reducing risk of complications and infections. $\mathrm{RCN}$ hand wash is a six-point, hand washing technique: palm to palm; right palm over left dorsum and left palm over right dorsum; palm to palm fingers interlaced; backs of fingers to opposing palm with fingers interlocked; rotational rubbing of right thumb clasped in left palm and vice versa; rotational rubbing, backwards and forwards with clasped fingers of right hand in left palm and vice versa. It takes an average of 34 seconds to complete, twenty seconds longer than normally washing hands. ${ }^{25} \mathrm{~A}$ brochure illustrating the RCN washing regimen may be given to patients (https:/cdifffoundation.org/ tag/ handwashing/).

\section{SCLERAL LENS CARE}

The care systems used for ScCLs are similar to corneal rigid gas permeable lenses. ScCL vault the cornea and the limbus creating a liquid reservoir underneath the lens. The liquid is in contact with the cornea and the limbus tissues during all wearing time. Rinsing ScCL after cleaning and disinfection in order to eliminate the cleaning and disinfecting agent is essential in pre-venting irritation and chemical toxicity of the cornea. The use of preservative-free saline to rinse $\mathrm{ScCL}$ is recommended.

A sterile, single dose, non-preservative saline solution is recommended to fill and rinse ScCL prior to 
application in the eye. The lenses should be overfilled until the single dose saline appears convex above the lens in order to prevent air bubble formation which can lead to corneal staining. Patients should be trained to identify air bubble formation after lens application in the eye using a mirror as a visual aid.

\section{CARE OF SCLERAL LENSES WITH TANGIBLE HYDRA-PEG COATING}

Tangible Hydra-PEG is a novel coating technology made from lubricant polyethylene glycol (PEG) which has been used for several years to improve lens surface wettability increasing tear break-up time, lubricity, minimizing friction and reducing protein and lipid deposits. ${ }^{26,27}$ It has been shown that the new surface option increases lens wearing comfort especially in patients suffering from contact lens-induced dry eye. ${ }^{28,29}$ Tangible Hydra-PEG is a $90 \%$ water PEGbased polymer mixture that is permanently bonded to the lens surface and can be applied to hydrogel, silicone hydrogel and RGP lens materials. ${ }^{30}$

ScCL with Tangible Hydra-PEG should be cleaned and disinfected every day. The surface coating is compatible with two multipurpose solutions, Boston Simplus (Bausch \& Lomb) and Menicon Unique pH Multipurpose Solution (Menicon), and two hydrogen peroxide solutions, Clear Care (Alcon) and Clear Care Plus with HydraGlyde (Alcon). Solutions that are alcohol based, abrasive and weekly cleaners should be avoided because they may damage the surface and reduce the benefits of the Hydra-PEG coating. ${ }^{31}$

\section{LENS CASE CARE}

Among all elements that interact between the contact lens and the care system, lens cases are likely the most neglected item due to the short time spent educating patients on its proper care. ${ }^{32}$ Bacteria attachment to internal case surfaces can lead to biofilm formation which is associated with complications such as MK. ${ }^{33-36}$ Several studies have shown the effectiveness of decreasing biofilm formation by rubbing, rinsing and wiping lens cases with a clean tissue $e^{16,37,38}$ followed by air drying storage cases face down on a clean tissue. ${ }^{39,40}$ Despite the fact that air drying storage cases is strongly recommended by several advisory bodies and the Food and Drug Administration, in the United States, only $50 \%$ of wearers agree to air drying cases. ${ }^{41}$

Silver impregnated cases necessitate a different management protocol. After rubbing and rinsing the cases they should be filled with fresh storage solution because the ions of argent are activated in the polymer blend when the environment is moist. Silver impregnated lens cases must be closed to prevent the evaporation of the solution and air-born contamination. Upon storage of ScCLs after removal from the eye, the silver impregnated case should be emptied, rinsed with saline solution and refilled with fresh solution.

The suggested protocol for lens case replacement is every month. Additional recommendations include replacing the case every time a new bottle of disinfecting solution is opened whenever a new case is available in the packaging. ${ }^{39}$

\section{PLUNGER CARE FOR APPLICATION AND REMOVAL}

Application and removal plungers, like lens cases, should be cleaned, rubbed, rinsed, tissue wiped and then allowed to air dry after each use. The same lens extra strength cleaner may be used for cleaning plungers. Alternatively, plungers may be cleaned with alcohol or alcohol wipes and then allowed to air dry.

Plungers must be replaced frequently. The Boston Foundation for Sight recommends plunger replacement every 6-12 months, or sooner whenever they are fractured or when edges become irregular as they may not provide good suction on the lens leaving residue on the lens surface.

\section{SCLERAL LENSES HANDLING: CORRECT APPLICATION AND REMOVAL TECHNIQUES}

The most common complications using ScCLs has been associated with lens handling. ${ }^{13}$ Patients should be educated on correct application and removal techniques to minimize and avoid ocular complications.

\section{Scleral Lens Application}

Manual and device methods may be used for ScCL application. In the manual methods, ScCL may be placed on two fingers, index and middle fingers, or three fingers, the thumb, index and middle fingers of 
the dominant hand. The device approach is an optimal alternative when handling ScCL is a challenge. It involves the use of a large DMV scleral cup (large plunger), or adaptive device such as the See Green ${ }^{\circledR}$ Lens Inserter and Stand, EZI Scleral Lens Applicator Ring, Number 8 "O" Ring and orthodontic ring (Figure 1). Non-preserved saline should be placed on any device used prior to lens application.

To apply a ScCL, patient should hold the edge of the lens while placing the lens on the plunger and gently squeeze the side of the plunger with the thumb and index fingers.

Once the lens is positioned on the device, the side pressure on the plunger may be released. Patient should lean the chin to the chest and have the head parallel to the ground, and the eyes opened wide by holding the upper and lower lid with the thumb and the index finger of the dominant eye. The lens overfilled with non-preserved saline may then be applied gently to the eye (Figure 2). After lens application, patient should check for the presence of air bubbles. If air bubbles are detected, ScCL should be removed and applied again.

\section{Scleral Lens Removal}

Before removing ScCL the eyes should be lubricated with non-preserved saline. Two methods may be used to remove the lens, the manual method and the device method. One manual method is as follows: Looking down, pushing the lower lid under the inferior lens edge and press the lid gently into the eye until the sealed pressure is released and then the lens may be removed. An alternative manual technique may be used whereby the patient presses the edge of the upper lid with the index finger, pushing the upper lid softly under the superior edge of the lens. With the index finger of the other hand, pressing the edge of the inferior lid under the inferior edge of the lens to block the ScCL from moving, looking upward until the sealed pressure is released and finally look up further and blinking gently to push away the upper lens edge from the eye with the upper lid margin.

The device method consists of using the DMV Ultra remover (small plunger), DMV classic or the DMV 45 angled. The device should be wet with nonpreserved saline before ScCL removal. The patient should hold the lids open, apply the plunger on the lens in the periphery, near the edge of the lens and gently push the lens away from the eye.

\section{RECOMMENDATION TOOLS}

\section{Instructions for ScCL Wearers}

The American Optometric Association proposed some recommendations for contact lens wearers concerning contact lens handling, wearing, solutions and cases with the aim of reducing the risk of infections related to contact lens use. ${ }^{42}$

Regarding ScCL use, further recommendations are suggested:

\section{Scleral lens handling}

1. Clean the ScCL daily by rubbing in the palms of the hands for 15 seconds with solution containing isopropyl alcohol in combination with a surfactant cleaner before the disinfection process. ${ }^{43}$

2. Disinfect ScCL daily.

3. Rinse the ScCL with preservative-free saline prior to application to remove debris, generally of organic origin, after the disinfection process.

4. Overfill the ScCL to the top until the non-preserved solution appears convex above the lens.

5. Disinfect application and removal devices, including plungers, after each use and then air dry them on a clean tissue.

6. Replace plungers every 6 months or before if they are damaged.

\section{Scleral lens wearing}

1. Inspect the lens for air bubbles after application in the eye.

2. Avoid sleeping in your lenses.

3 . Follow the recommended contact lens replacement schedule prescribed by your eye specialist

4. Observe your regularly scheduled follow-up visits for $\mathrm{ScCL}$ and eye examination.

\section{Scleral lens solutions and cases}

1. Use hydrogen peroxide solutions as a first choice for ScCL disinfection.

2. Use cases large enough to cover ScCL during storing and disinfection. 
FIG. 1 Scleral lens adaptive devices from top to bottom: See Green ${ }^{\circledR}$ Lens Inserter Stand, See Green ${ }^{\circledR}$ Lens Inserter, DMV scleral cup for application, large EZI Scleral Lens Applicator Ring, orthodontic ring, DMV Ultra remover, and small EZI Scleral Lens Applicator Ring.

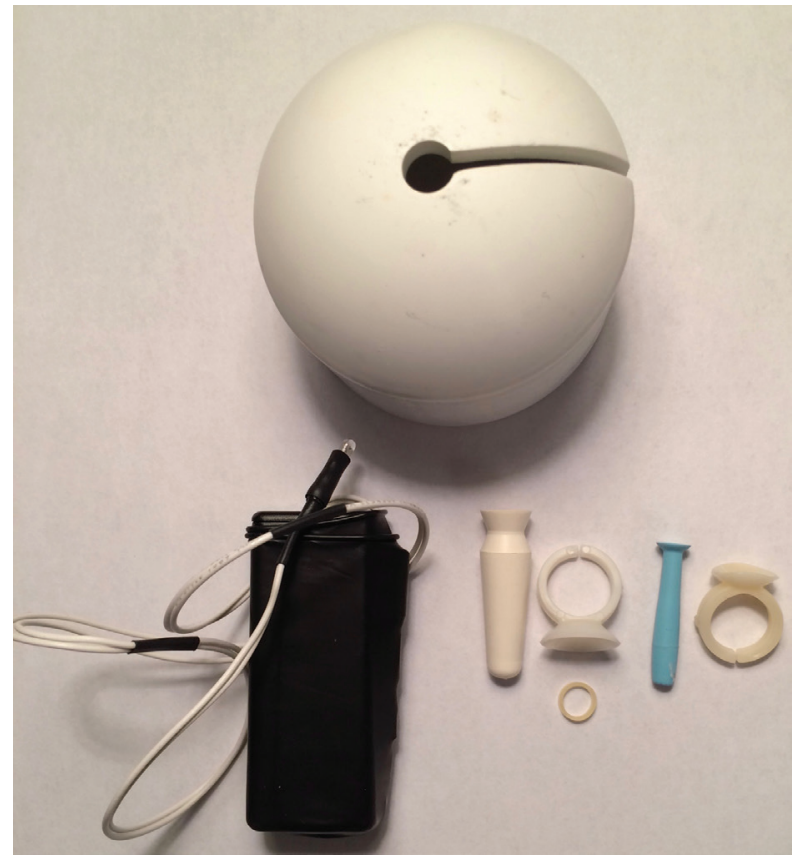

FIG. 2 Scleral lens application using the manual method.

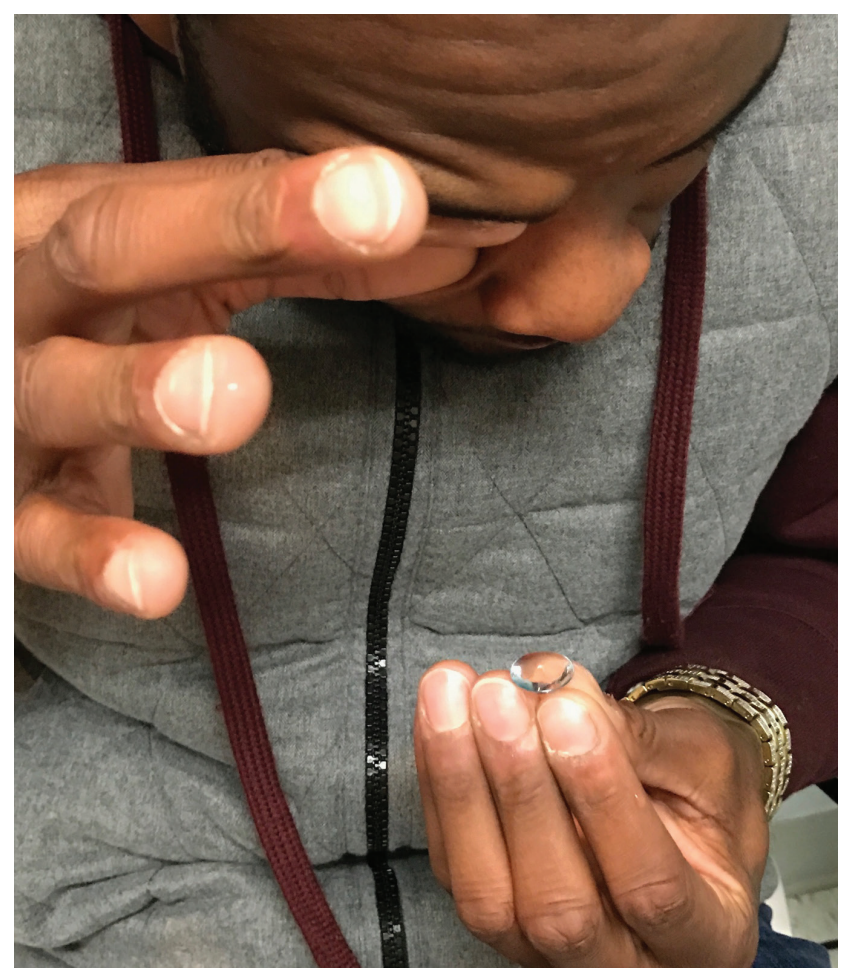

J Cont Lens Res Sci Vol 2(1):e22-e29; April 19, 2018

This article is distributed under the terms of the Creative Commons Attribution-Non Commercial 4.0 International License. 
3. Clean the ScCL case after lens application by rubbing the case then rinsing with multipurpose solution or saline solution and then air dry the case on a clean tissue. If it is a basket case allow it to air dry face up.

4. If the lens case is impregnated with argent, after lens application put some solution (saline or storing solution) inside the case and close it.

5. Use only preservative-free saline solution to fill the ScCL prior to application.

6. Use only application and removal devices and plungers recommended by your eye-care specialist.

7. If the care system package contains a new lens case, replace the case every time a new bottle of solution is used. If the care system package does not contain a new lens case, replace the case monthly or after three months maximum, taking care to clean the storage case daily.

8. Avoid placing lens cases in the bathroom.

Offering a brochure illustrating the different care procedures will help patients to remember the different steps and increase compliance. The brochure should also include a brief description of the importance of each phase of lens care.

\section{Verification of Patient Compliance}

To increase compliance, the instructions provided at the time of lens delivery should be verified and strengthened during follow-up visits. Observing the patient handling the lenses during each visit including follow-up visits is crucial to ascertain the level of compliance. ${ }^{44}$ Providing verbal and written instructions in addition to practical demonstrations has been shown to improve patient compliance. ${ }^{45}$

Using a questionnaire may be a supplementary tool. Morgan proposed a series of questions to ask patients during the follow-up visits. ${ }^{46}$ Below is an adaption of the questionnaire for use with ScCL:

1. Do you sleep overnight in your lenses?

2. Do you nap in your lenses?

3. How often do you sleep in your lenses?

4. Do you wash your hands before applying and removing lenses, and what with?

5. What do you use to clean/store your lenses?
6. Where do you store your lenses?

7. Do you replace your solution or add to existing solution instead of replacing solution?

8. Do you cover your lenses completely?

9. Do you close your lens case tightly?

10 . Do you clean your case?

11. How often do you change your case?

12. Do you close the cap of your bottle tightly?

13. When do you check the expiration date of your solution bottle?

14. How often do you replace your lenses?

15. What solutions do you use to fill the lenses?

16. What solutions do you use to disinfect and store lenses?

17. What device do you use for application and removal?

18. Do you disinfect your devices after each use? And what with?

19. How often do you replace your application and removal devices?

20. Do you inspect the lenses after application in the eye?

21. What case do you use to store lenses?

\section{CONCLUSIONS}

The authors acknowledge that there is no paper published describing in detail ScCL lens care, hygiene and compliance. This review summarized the modalities and implications of care, hygiene and compliance using ScCLs.

Practitioners should maintain a dialogue with patients and dedicate the necessary time to clarify to the patient the significance of hygiene and proper management of ScCLs, including lens cases and other devices. A brochure illustrating ScCL handling and aftercare will help increase the level of patient compliance. Recommendations provided should be verified and reviewed during follow-up visits. The practitioner should recognize patients who may report more compliance than is truly demonstrated upon examination.

With the continued spread of ScCL the risk of infections occurring may increase over time. To confirm this hypothesis more investigation is necessary on ScCL care and compliance. However, the number of ScCL wearers is still too low to make an epidemiologic study. 


\section{DISCLOSURES}

Authors disclose no conflicts of interest with any institution or product that is mentioned in this manuscript.

\section{REFERENCES}

1. Ruben CM, Benjamin WJ. Scleral contact lenses: preliminary report on oxygen permeable materials. Contact Lens J 1985;13:5-10.

2. Bleshoy H, Pullum KW. Corneal response to gas permeable impression scleral lenses. J Br Contact Lens Assoc 1988;11:31-4.

3. Pullum KW, Hobley A. Parker JH. The Josef Dallos Award Lecture, part two. Hypoxic corneal changes following sealed gas permeable impression scleral lens wear. J Br Contact Lens Assoc 1990;13:83-7.

4. Pullum KW, Hobley AJ, Davison C. 100+ Dk: does thickness make much difference? J Br Contact Lens Assoc 1991;6:158-61.

5. Mountford J, Carkeet N, Carney L. Corneal thickness changes during scleral lens wear: effect of gas permeability. International Contact Lens Clinic 1994;21(12):19-22. doi: 10.1016/0892-8967(94)90036-1

6. Zimmerman AB, Marks A. Microbial keratitis secondary to unintended poor compliance with scleral gas-permeable contact lenses. Eye Contact Lens 2014;40:e1-e4. doi: 10.1097/ ICL.0b013e318273420f

7. Walker M, Bergmanson JP, Miller WL, Marsack JD, Johnson LA. Complications and rifitting challenges associated with scleral contact lenses: A review. Cont Lens Anterior Eye 2016;39:88-96. doi: 10.1016/j. clae.2015.08.003

8. Rosenthal P, Cotter JM, Baum J. Treatment of persistent corneal epithelial defect with extended wear of a fluid-ventilated gas-permeable scleral contact lens. Am J Ophthalmol 2000;130:33-41. doi: 10.1016/S00029394(00) 00379-2.

9. Kalwerisky K, Davies B, Mihora L, Czyz CN, Foster JA, Demartelaere S. Use of the Boston ocular surface prosthesis in the management of severe periorbital thermal injuries: a case series of 10 patients, Ophthalmology 2012;119:516-21. doi: 10.1016/j.ophtha.2011.08.027.

10. Severinsky B, Behrman S, Frucht-Pery J, Solomon A. Scleral contact lenses for visual rehabilitation after penetrating keratoplasty: long term outcomes, Cont Lens Anterior Eye 2014;37:196-202. doi: 10.1016/j. clae.2013.11.001.
11. Fernandes M, Sharma S, Polymicrobial and microsporidial keratitis in a patient using Boston scleral contact lens for Sjogren's syndrome and ocular cicatricial pemphigoid, Cont Lens Anterior Eye 2013;36:95-97. doi: 10.1016/j. clae.2012.10.082.

12. Farhat B, Sutphin JE. Deep anterior lamellar keratoplasty for acanthamoeba keratitis complicating the use of Boston scleral lens, Eye Contact Lens 2014;40:e5-7. doi: 10.1097/ICL.0b013e3182997c4c.

13. Schornack M. Scleral lenses in current ophthalmic practice evaluation: SCOPE study updates. Presentation at the Global Specialty Lens Symposium. Las Vegas, 2017 January, 26-29.

14. U.S. Centers for Disease Control and Prevention. Acanthamoeba Keratitis among Rigid Gas Permeable Contact Lens Wearers - Talking Points April 20, 2016.

15. Sauer A, Meyer N, Bourcier T. Risk factors for contact lens-related microbial keratitis: a case-control multicenter study. Eye Contact Lens 2016;42:158-62. doi: 10.1097/ICL.0000000000000180.

16. Szczotka-Flynn LB, Imamura Y, Chandra J, Yu C, Mukherjee PK, Pearlman E, Ghannoum MA. Increased resistance of contact lens related bacterial biofilms to antimicrobial activity of soft contact lens care solutions. Cornea 2009;28(8):918-26. doi: 10.1097/ ICO.0b013e3181a81835.

17. Cope JR, Collier SA, Schein OD, Brown AC, Verani JR, Gallen R, Beach MJ, Yoder JS. Acanthamoeba keratitis among rigid gas permeable contact lens wearers in the United States, 2005 through 2011. Ophthalmology 2016;123(7):1435-41. doi: 10.1016/j.ophtha.2016.03.039.

18. Bruce, AS., Nguyen, LM. Acute red eye (non-ulcerative keratitis) associated with mini-scleral contact lens wear for keratoconus. Clin Exp Optom 2013;96:(2):245-8. doi:10.1111/cxo.12033

19. Rocha, GA., Miziara, PO., Castro AC., Rocha AA. Visual rehabilitatiaon using mini-scleral contact lenses after penetrating keratoplasty. Arq Bras Ofthalmo 2017;80(1):17-20. doi: 10.5935/0004-2749.20170006.

20. Morgan PB. Contact lens compliance and reducing the risk of keratitis. The Optician 2007;20-25.

21. Sokol JL, Mier MG, Bloom S, Asbell PA. A study of patient compliance in a contact lens-wearing population. CLAO 1990;J16(3):209-13.

22. Bowden T, Harknett T. Contact lens wearer profile 2004. Cont Lens Anterior Eye 2005;28:37-45. doi: 10.1016/j. clae.2004.10.002 
23. Claydon BE, Efron N. Non-compliance in contact lens wear. Ophthal Physiol Opt 1994;14:356-64.

24. Friedman DS, Hahn SR, Quigley HA, Kotak S, Kim E, Onofrey M, Eagan C, Mardekian J. Doctor-patient communication in glaucoma care: analysis of videotaped encounters in community-based office practice. $O p h$ thalmology 2009; 116. 2277-2285.e1-3. doi: 10.1016/j. ophtha.2009.04.052

25. Campbell D, Mann A, Hunt O, Santos LJR. The significance of hand wash compliance on the transfer of dermal lipids in contact lens wear. Cont Lens Anterior Eye 2012;35:71-76; quiz 96-7. doi: 10.1016/j. clae.2011.11.004. Epub 2011 Dec 16.

26. Ousler GW, Michaelson C, Christensen MT. An evaluation of tear film breakup time extension and ocular protection index scores among three marketed lubricant eye drops. Cornea 2007;26:949-52. doi: 10.1097/ ICO.0b013e3180de1c38

27. Fonn D. The clinical relevance of contact lens lubricity. Contact Len Spectrum 2013;28:25-27.

28. Jones L, Brennan NA, Gonzalez-Meijome J, et al. The TFOS International Workshop on Contact Lens Discomfort: Report of the Contact Lens Materials, Design, and Care Subcommittee. Invest Ophthalmol Vis Sci 2013;54 (11) : TFOS37-70). doi: 10.1167/iovs.13-13215

29. Caroline, P. et al. Hydra-PEG: A Solution to Contact Lens Discomfort? Poster presented at Global Specialty Lens Symposium 2015.

30. Sindt CW. The great silicone cover-up. Rev Cornea Cont Lens 2015;4:7.

31. Sindt CW. Tangible Hydra-PEG: A novel custom contact lens coating technology designed to improve patient comfort and satisfaction. Available at: https://www. artoptical.com/storage/docs/THP_White_Paper.pdf.

32. Lupelli L. Il contenitore: il brutto anatroccolo della contattologia. LAC 2010;12:3-6.

33. Wu, Y, Willcox M, Stapleton F. The effect of contact lens hygiene behavior on lens case contamination. Optom Vis Sci 2015;92(2):167-74. doi: 10.1097/ OPX.0000000000000477.

34. Wiley L, Bridge DR, Wiley LA, Odom JV, Elliott T, Olson JC. Bacterial biofilm diversity in contact lensrelated disease: emerging role of Achromobacter, Stenotrophomonas, and Delftia. Invest Ophthalmol Vis Sci 2012;53(7):3896-905. doi: 10.1167/iovs.11-8762.
35. Bates AK, Morris RJ, Stapleton F, Minassian DC, Dart JK. 'Sterile' corneal infiltrates in contact lens wearers. Eye 1989;3(Pt. 6):803-10. doi: 10.1038/eye.1989.124

36. Willcox MD. Solutions for care of silicone hydrogel lenses. Eye Contact Lens 2013;39(1):24-8. doi: 10.1097/ ICL.0b013e318275e0d9.

37. Wu YT, Zhu H, Willcox M, Stapleton F. The effectiveness of various cleaning regimens and current guidelines in contact lens case biofilm removal. Invest Ophthalmol Vis Sci 2011;52(8):5287-92. doi: 10.1167/iovs.10-6785.

38. Wu YT, Teng YJ, Nicholas M, Harmis N, Zhu H, Willcox MD, Stapleton F. Impact of lens case hygiene guidelines on contact lens case contamination. Optom Vis Sci 2011;88(10)1180-7. doi: 10.1097/OPX.0b013e3182282f28.

39. Sweeney D, Holden B, Evans K et al. Best practice contact lens care; a review of the Asia Pacific Contact Lens Care Summit. Clin Exp Optom 2009;92(2):78-89. doi: 10.1111/j.1444-0938.2009.00353.x.

40. FDA. Ensuring safe use of contact lens solution. 2017. Available at: www.fda.gov/forconsumersupdates/ umc166549.htm.

41. Wu Y, Carnt N, Willcox M, Stapleton F. Contact lens and lens storage case cleaning instructions: whose advice should we follow? Eye Contact Lens 2010;36(2):68-72. doi: 10.1097/ICL.0b013e3181cf8aff.

42. American Optometric Association. Contact Lens Care and Use. 2017. Available at: https://www.aoa. org/documents/CRG/Contact $\% 20$ Lens $\% 20$ Care $\% 20$ and $\% 20$ Use $\% 20$ Guide.pdf).

43. Sticca M, Carvalho C, Silva I, Souza L, Belfort R, Carvalho $\mathrm{R}$, Freitas D. Acanthamoeba keratitis in patients wearing scleral contact lenses. Con Lens Ant Eye; 2017. Available at: https://doi.org/10.1016/j.clae.2017.12.004.

44. Hickson-Curran S, Chalmer RL. Patient attitudes and behavior regarding hygiene and replacement of soft contact lenses and storage cases. Cont Lens Anterior Eye 2011;34(5):207-15. Epub 2011 Jan 11. doi: 10.1016/j. clae.2010.12.005.

45. Tilia D, Lazonde la Jara P, Zhu H. The effect of compliance on contact lens case contamination. Optom Vis Sci 2014;91(3):262-71. doi: 10.1097/OPX.0000000000000163.

46. Morgan PB, Efron N, Toshida H., Nichols JJ. An international analysis of contact lens compliance. Cont Lens Anterior Eye 2011;34(5):223-28. Epub 2011 Aug 24 doi: 10.1016/j.clae.2011.08.001.

J Cont Lens Res Sci Vol 2(1):e22-e29; April 19, 2018

This article is distributed under the terms of the Creative Commons Attribution-Non Commercial 4.0 International License. 